\title{
Universidades, sistema de innovación e políticas científicas e de investigación en Galicia. 25 anos da creación das novas universidades galegas
}

\author{
Universities, Innovation System, Scientific and Research Policies in \\ Galicia: 25 Years after the Creation the the New Galician Universities
}

\author{
Xulia GUNTÍN ARAUJO \\ (Departamento de Economía Cuantitativa. USC) \\ Lourenzo FERNÁNDEZ PRIETO \\ (Departamento de Historia Contemporánea. USC)
}

\begin{abstract}
RESUMO: Considerando o coñecemento como motor da innovación nas sociedades modernas queremos repasar as capacidades de Galicia neste ámbito e valorar o nivel actual de aproveitamento das mesmas. A afirmación de que o coñecemento é o motor da innovación nas sociedades modernas poucos se atreven a negala no mundo actual. $O$ que nos interesa aquí é como entendela en Galicia hoxe, a partir dunha observación panorámica do sistema galego de innovación, que atende especialmente aoseu motor universitario. Co gallo dos 25 anos da creación das universidades da Coruña e Vigo, optamos por una análise de presente e de futuro fronte á relembranza do que foi aquel proceso de segregación, do que se ten dito e escrito non pouco.
\end{abstract}

PALABRAS CHAVE: Universidades, Investigacion, Educacion superior, Politicas científicas, Sistema de innovacion.

ABSTRACT: Based on the assumption that knowledge is the driving force behind innovation in modern societies, this article attempts to review Galicia's capabilities in this field and to assess the extent to which they are currently being used to their full potential. Few people living in today's world would dare to deny the above assertion that knowledge is the driving force behind innovation in modern societies. What interests us here is how to interpret it in Galicia today, using a panoramic observation of Galicia's innovation system, which serves the university's driving force. On the occasion of the 25th anniversary of the creation of the Universities of A Coruña and Vigo, our analysis will focus on the present and the future rather than going back to remember the separation process, about which much has been written and said.

KEY WORDS: Universities, Research, Higher education, Scientific policies, Innovation System 


\section{Introdución}

O coñecemento é motor da innovación e por iso interesa, en primeiro lugar, recoñecer as nosas capacidades en produción de coñecemento e xeración da innovación para poder facelas aproveitables. Recoñecendo tamén as limitacións dun sistema maduro e necesariamente limitado dadas as posibilidades do mundo de hoxe. Mais cómpre ter en conta que algunhas destas limitacións establecémolas nós mesmos sen pretendelo e son mesmo ideolóxicas cando non propias de autocolonizado, mentres outras podemos obxectivalas ao comparar o sistema galego con outros sistemas de educación superior e investigación. En calquera caso, o lema do que habitualmente parten as políticas educativas e de innovación, que vén sendo algo así como "prepara persoas e constrúe a economía do futuro" non deixa de ser tan ilustrado como aquelas arelas dos devanceiros que desde hai dous séculos procuraron o benestar e a mellora social pola vía da formación e aínda enlaza coas angueiras paternas que desde hai medio século buscaron lograr, a través da formación dos seus fillos e fillas, unha sociedade máis culta, formada e dialogante que aquela da que eles fixeran parte.

Como estamos en tempo de pensar, partimos de varias preguntas que cómpre facerse a estas alturas: conformámonos con ser unha sociedade plenamente alfabetizada como era 0 obxectivo (porén aínda discutido por algúns sectores) hai 100 anos? Posiblemente responderiamos que non. É un luxo a formación universitaria para lograr unha sociedade máis culta, máis sabia e máis humanista? Parece que hai un certo consenso social en non querermos renunciar a este desexo. Acadamos os niveis educativos que arelabamos? A resposta sería que non coñecemos o límite, pero tampouco todos estariamos de acordo.

Ata aquí o coñecido e máis ou menos recoñecido, pero unha vez conseguidas as condicións para 0 acceso á educación superior de case todos os que queren estudar, se ollamos cara a diante as preguntas que é necesario facerse non son tan evidentes ${ }^{1}$. A primeira podería ser cal é o grande obxectivo social que pretendemos lograr coa educación superior. A segunda como concretamos aquí e agora o que denominamos sociedade do coñecemento. A terceira como definimos estratexias para un sistema de $\mathrm{I}+\mathrm{D}$ galego nun horizonte de 50 anos.

De entrada, as respostas a estas preguntas pasarían por recoñecer que somos sociedades ricas europeas que podemos sustentar esta aspiración, e que igual que solucionamos problemas do benestar, da saúde e da atención aos vellos, queremos, e tamén podemos, construír unha sociedade máis sabia e unha forma de vivir sustentable, baseada no coñecemento.

O que nos interesa neste breve ensaio é indagar e propor algunhas solucións de futuro para lograr que a investigación universitaria en Galicia preste servizo á sociedade e ao país de xeito que a educación superior siga cumprindo unha das súas funcións máis coñe-

\footnotetext{
${ }^{1}$ Esas condicións -aínda que hoxe poidan considerarse en risco- parece que lograron ser establecidas nas últimas catro décadas, pois teñamos en conta que aínda en 1970 só cursaba bacharelato $027 \%$ dos que fixeran primaria e só o $3 \%$ do total chegaban á universidade.
} 
cidas e apreciadas: a de ser unha das bases do desenvolvemento social e económico. Necesitamos reflexionar sobre as boas prácticas pasadas porque iso permitirá aproveitar mellor as nosas vantaxes comparativas en termos de coñecemento. E tamén sobre os erros, para redimensionar e reformar as estruturas e as culturas vinculadas ao coñecemento $e$ a innovación na Galiza. En todo caso, estamos certos de que cómpre pensar e deseñar novas políticas e trátase de contribuír a pensalas. Despois de 25 anos vai sendo hora de repensar a educación superior no ámbito do sistema de innovación. Esíxeno os tempos.

Nese camiño, o guión que seguimos atende ao seguinte esquema de diagnose, valoración e proposta:

1. Diagnose do sistema científico de educación superior para evidenciar que temos un sistema relativamente maduro e homologable. Apreciarmos que potencia ten 0 sistema galego de educación superior e mais o de $\mathrm{I}+\mathrm{D}$, facendo un breve repaso ao sistema e unha valoración da súa potencialidade. QUE TEMOS?

2. Valoración das políticas realizadas nas últimas dúas décadas e os seus resultados, para comprobar como construímos o sistema universitario e de investigación, e cal é a súa dinámica e cales son as súas inercias. Trátase de saber como o usamos hoxe, para que o queremos, como o financiamos e que lle estamos a pedir. En resumo: QUE ESTAMOS FACENDO CO QUE TEMOS?

3. Que lle queremos pedir ao sistema que faga. Que políticas poden deseñarse. Como pode servir o sistema que temos para o que o queremos. Necesitamos saber que queremos, que lle pedimos ao sistema que faga e iso require pensar no deseño de políticas. Tamén en que retorno podemos esixirlle ao sistema de educación superior e innovación. Dito doutro xeito, QUE LLE QUEREMOS PEDIR AO SISTEMA QUE FAGA?

\section{Que temos? Unha breve diagnose do sistema científico e de educación superior}

Para o recoñecemento das nosas capacidades reais neste terreo e das nosas posibilidades como país, cómpre superar de vez a síndrome da universidade única galega e asumir que o sistema universitario galego está conformado desde hai 25 anos por tres universidades². O non recoñecemento desta evidencia convértese, por veces, nunha síndrome limitante que nos mingua como país e como sistema universitario e de investigación, que nega o que medraron as universidades galegas e desfigura os obxectivos sociais e formativos que cumpriron nos últimos anos, levando a unha percepción negativa de principio que nega as vantaxes do sistema de que dispomos.

\footnotetext{
${ }^{2}$ En realidade desde hai máis de 40 anos, tendo en conta que os actuais sete campus tiñan colexios universitarios e centros dende a aplicación da Lei xeral de educación de 1970. E mesmo 150 anos, se temos en conta a actividade das escolas de Comercio e das escolas normais provinciais que deviñeron en facultades universitarias no último medio século.
} 
Nega, ademais, a capacidade do autogoberno galego para ter tomado decisións oportunas mesmo 25 anos despois de telo feito, con consecuencias ideolóxicas e políticas evidentes. Unha mestura de aristocratismo académico, romantismo estudantil retrospectivo e incapacidade para pensar nun país ambiciosamente autogobernado está detrás desta señardade, moi presente aínda entre as elites económicas, políticas e mesmo académicas do pais (nacionalismo incluído). Non é infrecuente nin estraño, para a esquerda e a dereita, para o nacionalismo e o españolismo, situar a división da Universidade de Santiago en 1990!!!, como razón fulcral de todos os males da universidade galega desde aquela até o presente. Esta síndrome da Universidade única axuda moito a non pensar e facilita non procurar solucións aos problemas reais.

Calquera comparación pode levar a erros, pero sempre pode axudar a situar e ponderar. Pensar nunha soa universidade na Galicia de hoxe lévanos a compararnos con Asturias ou Cantabria (por falar de universidades únicas de comunidade autónoma e con tradición), ou coa Rioxa, pois Murcia conta con tres (unha universidade privada católica e a Politécnica pública de Cartaxena, ademais da histórica Universidade de Murcia). Certo que Euskadi mantén unha soa pública (a UPV), pero con tres campus (non sete como sería aquí) e con duplicación considerable de estudos e profesorado nos tres campus, nun territorio máis pequeno que o galego e con menos poboación, pero ademais conta con dúas privadas (a clásica de Deusto e a nova de Mondragón), e se sumamos Navarra en Euskal Herría falamos xa de cinco universidades para unha poboación igual á de Galicia. Por non falarmos das 9 universidades públicas andaluzas (máis a Internacional de Andalucía), das 13 catalás (7 públicas, 5 privadas e a UOC autonómica) ou das 14 madrileñas (6 públicas, 7 privadas e a UDIMA autonómica). Pensar no desenvolvemento das capacidades formativas e investigadoras de Galicia do último cuarto de século, borrando as tres universidades realmente existentes, creadas por un goberno tripartito en 1990 é simplemente unha ucronía distópica. Mellor recorrer a un cultismo que chamarlle simplemente insensatez, pero é unha insensatez que, no entanto, partillan non poucos dos nosos concidadáns e gran parte das elites, ata 0 extremo de converterse nunha idea tan estendida como contraria á realidade, como vimos de indicar. Se, alén de España, ollamos Europa e o resto do mundo un panorama semellante confirma o noso razoamento.

A idea da universidade galega única, ademais de síndrome, é un álibi porque sendo impracticable neste intre, úsase para animar retallos financeiros por conta da crise, autoimpón límites que prexudican as capacidades propias en beneficio das alleas e favorece e mesmo disimula as limitacións dos actuais gobernantes sobre as capacidades das universidades galegas. Introducindo unha perversa lóxica que confunde mellorar o sistema con reducilo, e reformalo con retirarlle capacidade e transferirlle ao Estado funcións e mesmo medios (programas de recursos humanos, de investigación etc...) que hoxe forman parte do noso autogoberno. Unha autolimitación que, ademais, abre a porta á sempre desexada (pola dereita política e ideolóxica) implantación de universidades privadas con axuda pública, ou o apoio á UNED, en vez de pular a nosa propia universidade a distancia, por parte de todos os gobernos que houbo en Galicia, incluídos os das deputacións provinciais. Como non interpretar a publicidade que as novas universidades a distancia (a UDIMA e 
a Oberta de Catalunya) gastan anualmente nos medios de comunicación galegos, senón entendendo que reflicten unha demanda de estudos (a maiores da matrícula na UNED tradicional) aínda non ben cuberta e á que non dan respostas as políticas universitarias galegas?

Ademais de recoñecer o rol da estrutura universitaria, é necesario referirse á existencia dunha infraestrutura para a investigación formada por centros universitarios e non universitarios, en sectores estratéxicos e emerxentes (no ámbito agrario e mariño, industrial, TIC), que constitúe unha importante realidade e unha potencial rede de centros de investigación e innovación.

En conxunto, a evolución do sistema de investigación en Europa, e dentro del o das universidades galegas, amosou nas dúas últimas décadas un claro avance tanto na súa dotación de recursos humanos como de recursos físicos, grandes infraestruturas e infraestruturas científico-tecnolóxicas de menor dimensión. En Galicia esta medra foi protagonizada fundamentalmente polas universidades, de forma máis acentuada nas dúas últimas décadas (1990-2010), consecuencia da combinación da expansión da demanda de estudos universitarios e das dinámicas do seu propio persoal docente e investigador.

En troques, non houbo un crecemento parello do sistema público de innovación/investigación non universitario en Galicia. $O$ certo é que en ausencia dun organismo galego de investigación dependente da Administración autonómica, o único organismo público capaz de impulsar ese crecemento de centros de investigación era o CSIC, mais este organismo dependente do goberno central, que no pasado si establecera centros en Galicia ou recreara centros anteriores a 1936, nas últimas décadas desatendeu -máis ben viu frustrada- a creación e o impulso de centros en Galicia ${ }^{3}$. Así pois, sen o vello impulso do CSIC ou de ministerios como o de Agricultura e sen un novo impulso procedente da Administración autonómica, ningunha outra instancia impulsou ese desenvolvemento de centros de investigación fora do ámbito universitario e no marco dunha política pública decidida.

$\mathrm{Na}$ actualidade, o sistema galego de investigación no seu sentido máis estrito conta con cinco centros de investigación vinculados ao CSIC, dous deles de carácter mixto (a Misión Biolóxica de Galicia coa Deputación de Pontevedra e o Instituto Padre Sarmiento de Estudos Galegos coa Xunta), xunto co de Investigacións Agrobiolóxicas en Santiago e o de Investigacións Mariñas en Vigo. Cómpre sinalar que unicamente o Instituto de Ciencias do Patrimonio (INCPT) é de creación recente. O CSIC, como axencia estatal de investigación, non ten desenvolvida unha estratexia de expansión e consolidación de centros de investigación en Galicia como si fixo noutros territorios do Estado. Dos 31 novos centros creados desde 1986, unicamente un foi instalado en Galicia, o xa mencionado INCIPT, creado no ano 2009 e que formaba parte dunha proposta máis ampla xa esquecida, e que de feito segue sen botar a andar como debera, paralizado pola crise. A isto súmanse as dúas sedes do Instituto Español de Oceanografía.

\footnotetext{
${ }^{3}$ Como a Misión Biolóxica de Galicia da JAE (1921) ou o Seminario de Estudos Galegos (1923), vinculado á Universidade de Santiago e convertido polo CSIC en IEGPS despois de 1939.
} 
O panorama de centros de investigación non universitarios complétase cos centros de investigación propios da Xunta de Galicia na actualidade. Trátase do Centro de Investigacións Agrarias de Mabegondo (CIAM) que antes das transferencias era 0 antigo CRIDA-01 do INIA (herdeiro da Granxa Agrícola Experimental da Coruña creada en 1888) e a Estación Enolóxica de Ribadavia (EVEGA), creada xa pola Xunta de Galicia (ambos están agrupados no Instituto Galego da Calidade Alimentaria ou INGACAL). Complétase esta infraestrutura cos centros de investigacións Mariñas de Corón-Vilaxoán e mais o de Ribadeo, agrupados no CIMA ou Centro de linvestigacións en Marisqueo. Algúns destes centros xorden da necesidade das administracións de contaren con servizos propios de análise, proba, demostración e control, e as súas funcións semellan aínda na actualidade máis as propias dun centro de innovación e servizos que as que se atribúen aos centros de investigación, cando menos na súa formulación máis clásica.

Desde o punto de vista das áreas de investigación, podemos concluír que a vocación investigadora destes centros está maioritariamente ligada aos recursos naturais, agrarios e mariños. $O$ que ten un significado claramente de pasado, atendendo ao papel asignado historicamente a Galicia polas administracións do Estado, mesmo de presente (aproveitar os nosos recursos), pero carente de enxergarse nunha estratexia de futuro máis complexa e multisectorial.

Fronte a esta fotografía case fixa, as universidades galegas amosaron, pola contra, unha grande evolución das súas estruturas, impulsadas por cambios nas orientacións das recomendacións e nas políticas de investigación, emanadas nos últimos anos en boa parte da UE, ás que foron respondendo con certa elasticidade.

De forma especial na década dos 90 e primeiros anos do século XXI, previos ao inicio da crise económica, foron anos en que, ao igual que noutras áreas da nosa economía, se apostou pola creación de infraestruturas físicas -polo continente- entendendo que as carencias en infraestruturas eran un obstáculo esencial para o desenvolvemento da capacidade investigadora latente no noso país. A expansión no número de edificios que acollen centros e outras estruturas para a investigación é evidente para calquera cidadán. Non hai máis que pasear polo Campus Sur da Universidade de Santiago, rebautizado na actualidade Campus Vida. Estas novas infraestruturas puideron desenvolverse grazas aos fondos FEDER que as financiaron nunha porcentaxe moi elevada. Pasada a urxencia de creación de facultades motivada polo gran crecemento na matrícula ao longo dos anos 90, o tipo de estruturas que se crean xusto antes da crise son centros para a investigación concibidos como lugares de encontro de certo carácter interdisciplinar dentro dunha orientación investigadora concreta: 0 Centro de Investigación en Medicina Molecular e Enfermidades Crónicas (CIMUS) da USC, a Estación das Ciencias Mariñas de Toralla (ECIMAT) na UVigo ou o Centro de Innovación Tecnolóxica en Edificación e Enxeñaría Civil (CITEEC) da UDC. Son espazos específicos para a investigación que aloxan grupos que abordan unha mesma área de traballo desde diversas aproximacións, ou cando menos esa é a idea que os motiva.

O mapa de centros de investigación actual respondeu de forma case exclusiva ás decisións autónomas de cada universidade que estableceu as súas propias prioridades 
en dotación de infraestruturas. $O$ deseño global carece posiblemente de falta de visión de conxunto. Coma noutros ámbitos primou a competencia fronte á cooperación, a consideración das outras universidades como rivais en vez de como socios estratéxicos para a xeración de sinerxías a prol do sistema no seu conxunto. Certamente a lóxica de financiamento universitario establecida pola Xunta xogou a favor desta forma de comprender as relacións entre as tres universidades do sistema.

Así, por exemplo, en todo este tempo, en realidade desde a creación na Universidade de Santiago do Instituto da Lingua Galega e do Instituto Universitario de Estudos e Desenvolvemento de Galicia na década de 1970, non se creou en Galicia ningún novo centro de investigación en ciencias sociais ou humanas, apenas tampouco en ciencias agrarias. A sobrerrepresentación das ciencias químicas e da vida (bioloxía, química e medicina) protagonizou toda a expansión dos tempos democráticos e autonómicos.

\section{Que estamos facendo co que temos?}

Asumida a realidade das tres universidades como inapelable e necesaria, daquela quizais podemos apreciar algunhas das vantaxes comparativas do SUG en termos formativos que, adecuadamente recoñecidas e aproveitadas, nos poidan permitir unha mellora da nosa posición no contexto europeo e mundial. Ningunha sociedade que acadou un sistema de educación superior maduro prescinde del ou o reduce, ao contrario, faino render, de non mediaren circunstancias extremadamente anormais ou catastróficas.

En primeiro lugar, é de constatar unha experiencia alargada na formación de graduados e doutores nas últimas tres décadas que dotan o sistema dunha capacidade formativa contrastada e que produciron un bo cadro de recursos humanos formados ao máis alto nivel (cadro 1). Non obstante, aínda se aprecia un importante percorrido por facer en comparación coas comunidades españolas máis dinámicas. A idea de que hai exceso de titulados en Galiza compadécese mal coa realidade e, sobre todo, coas aspiracións de mellora social e económica que agocha esta comparanza. E a idea de que hai exceso de titulados para as capacidades de atracción do sistema produtivo é simplemente propia dunha lóxica autolimitante demasiado estendida nalgúns sectores da sociedade galega.

CADRO 1: Porcentaxe de poboación con titulación superior (incluído doutoramento) sobre a poboación activa total en Galicia e outras comunidades autónomas ${ }^{4}$

\begin{tabular}{|l|c|c|c|c|c|c|}
\hline & $\mathbf{2 0 1 3}$ & $\mathbf{2 0 1 3}$ & $\mathbf{2 0 1 0}$ & $\mathbf{2 0 1 0}$ & $\mathbf{2 0 0 5}$ & $\mathbf{2 0 0 5}$ \\
\hline & Homes & Mulleres & Homes & Mulleres & Homes & Mulleres \\
\hline Galicia & $38,27 \%$ & $50,03 \%$ & $35,30 \%$ & $48,20 \%$ & $33,02 \%$ & $46,15 \%$ \\
\hline Madrid & $55,55 \%$ & $59,83 \%$ & $47,81 \%$ & $55,00 \%$ & $42,39 \%$ & $53,13 \%$ \\
\hline País Vasco & $62,38 \%$ & $67,65 \%$ & $57,33 \%$ & $64,26 \%$ & $52,08 \%$ & $64,21 \%$ \\
\hline Cataluña & $37,86 \%$ & $48,43 \%$ & $34,64 \%$ & $43,43 \%$ & $32,52 \%$ & $43,43 \%$ \\
\hline
\end{tabular}

Fonte: Elaboración propia a partir do Instituto Nacional de Estatística

\footnotetext{
${ }^{4}$ Escollemos aquelas comunidades que constitúen ademais o destino preferente da emigración galega.
} 
Nun contexto de globalización e de ampliación da demanda de estudantes internacionais, a capacidade formativa das universidades galegas pode ser aproveitada a nivel global -pero con retornos evidentes no interior-, ao xeito do que fan algunhas universidades francesas e principalmente británicas. A capacidade de atracción de estudantes estranxeiros (europeos e extraeuropeos), ben contrastada, é aínda maior no caso dos alumnos de mestrado e doutoramento, que en universidades como a de Santiago supoñen nos últimos anos por volta do $25 \%$ do total $\left.\right|^{5}$.

De feito, a realidade dos últimos tempos xa demostra por parte das universidades galegas non só unha posibilidade, senón unha máis que evidente capacidade de atracción de estudantes europeos (Erasmus), de estudantes americanos e de países emerxentes (Brasil, Perú, Colombia, Angola, Namibia...), para os que as universidades galegas se revelan unha ponte privilexiada de Europa con América/África pola singularidade das súas dúas linguas. $E$ isto aconteceu con moi escasas e puntuais políticas activas por parte do goberno da autonomía que, de feito, aínda non deu reparado adecuadamente na importancia desta realidade e na súa potencialidade para situarse nunha mellor posición xeoestratéxica, como simple forma de vantaxosa participación no proceso de globalización actual ou, nunha aspiración aínda máis modesta, como ingreso para o financiamento das universidades e do sistema universitario galego.

A pregunta decisiva, en todo caso, é que facer con tanta capacidade de formación e como integrar os máis formados en vez de facelos emigrar? Como podemos aproveitar os mellores? A resposta non é doada, pois as capacidades para absorber os titulados dependen da densidade do sistema económico e do sistema de innovación e non só da capacidade de emprendemento dos titulados, como pretenden facer ver algúns cunha verborrea neoliberal que queren facer pasar por políticas.

En todo caso, este país necesita clarificar para que quere no século XXI o seu sistema de educación superior. Tendo en conta a redución do financiamento (un 15\% en 2013 respecto ao 2009, nas principais partidas da actividade universitaria), diríase que sobra SUG. Tendo en conta as políticas dos últimos gobernos do Partido Popular, que dan a entender que non saben para que queren este sistema universitario, que se foi construíndo na maioría dos casos a pesar deles, diríase que preferirían reducilo. Cumpridas as tarefas do pasado -formar titulados ata un nivel semellante ao doutros países do contorno-, chega o momento de preguntarse que futuro queremos para o sistema universitario galego e 0 contexto de crise é un bo momento para facérmolo.

No ámbito da investigación, unha vez que a urxente necesidade de infraestruturas xa está suficientemente cuberta, desvélase que debe haber outros problemas esenciais, froito da percepción do escaso impacto e/ou das dificultades de traducir o esforzo investi-

\footnotetext{
${ }^{5}$ Véxanse os informes das universidades galegas sobre estudantes internacionais. Santiago sitúase no posto $25 .{ }^{\circ}$ en recepción de Erasmus, un $15 \%$ dos seus estudantes provén de fóra de Galicia, e un $6 \%$ é estranxeiro, a metade de orixe europea e a outra metade extraeuropea (datos de 2008).
} 
gador en avances sociais e económicos para o país, tanxibles e valorables. De xeito que se descobre que o problema xa non era de infraestruturas senón doutra natureza.

Certamente esta percepción está ligada á diagnose que en Europa se está a realizar sobre a debilidade do sistema de innovación europeo. Desde Europa faise fincapé na necesidade de mellorar a transferencia do coñecemento xerado nos centros de investigación, de facer do coñecemento o motor para recuperar a competitividade global perdida e de reducir o gap entre investigación e mercado 6 .

A grandes trazos, no caso galego isto foi entendido por parte das universidades de dúas formas xa desde comezos deste século XXI:

a) Promoción das iniciativas de spin-off das universidades, (impulsando instrumentos diversos para a súa promoción: incubadoras, capital semente, unidades de asesoramento...). A vixente Lei orgánica de universidades 6/2001, do 21 de decembro7; e a súa modificación mediante a Lei orgánica 4/2007, do 12 de abril ${ }^{8}$, son textos normativos que de forma clara nos seus obxectivos perseguen favorecer e impulsar a vocación de transferencia do sistema universitario.

b) Achegamento á investigación industrial e desenvolvemento tecnolóxico coa colaboración máis próxima e estable co tecido empresarial (participación nas plataformas tecnolóxicas, colaboración cos centros tecnolóxicos). A Universidade de Vigo acolle nas súas dependencias a GRADIANT ou a EnergyLab; a Universidade da Coruña pon en marcha o seu propio parque tecnolóxico.

Estes cambios foron animados pola acción dos gobernos. Entre 2005 e 2009, en Galicia o goberno bipartito alentou e enxergou as súas políticas con esta dinámica dun xeito ben acompasado, anovado e incisivo a respecto das mornas experiencias previas. 0 punto de partido foi unha diagnose sobre a existencia dunha capacidade investigadora e innovadora mal aproveitada, nun contexto de reducido esforzo innovador por parte do tecido empresarial do país. Daquela, coma hoxe, o resultado desexable era e segue a ser a consolidación da innovación na estratexia empresarial, sen menoscabo da necesaria continuidade e expansión da I+D realizada no sector público, sobre cuxa base deben asentarse os proxectos innovadores que favorezan o desenvolvemento social e económico de Galicia.

Os datos entre 2006 e 2012 indican que, aínda que de forma non consolidada, este reequilibrio do sistema galego de ciencia e innovación deu uns primeiros pasos.

Desde 2006 o persoal investigador do sector empresarial experimenta un crecemento constante aínda na etapa de crise económica. Porén, o crecemento que o emprego tivo no sector público, maioritariamente universitario, entre 2006 e 2010, foi conxugado co drástico recorte de persoal investigador que sufriu esta parte esencial do sistema desde 0 inicio da crise, de tal forma que o saldo entre 2006 e 2014 é negativo, cunha perda significativa

\footnotetext{
${ }^{6} \mathrm{http}: / /$ www.eshorizonte2020.es/

${ }^{7} \mathrm{BOE},$. n. -307 do 24 de decembro de 2001.

${ }^{8}$ BOE $n \div 89$ do 13 abril 2007.
} 
de recursos humanos. A este respecto, o seguinte cadro é altamente significativo dunha tendencia derivada das políticas -ou máis ben da ausencia de políticas activas- nos últimos anos.

CADRO 2. Evolución do número de investigadores entre 2006, 2010 e 2014 en Galicia e España. Comparación entre o sector de universidades e o total.

\begin{tabular}{|l|c|c|c|c|} 
& Var. 2006-10 & Var. 10-14 & \% Galicia / España 2010 & \% Galicia / España 2014 \\
\hline Universidades & & & & \\
\hline España & $16,50 \%$ & $-11,51 \%$ & $6,32 \%$ & $5,25 \%$ \\
\hline Galicia & $27,72 \%$ & $-26,49 \%$ & & \\
\hline Total & & & & $4,48 \%$ \\
\hline España & $16,28 \%$ & $-9,22 \%$ & $4,96 \%$ & \\
\hline Galicia & $28,74 \%$ & $-18,11 \%$ & &
\end{tabular}

Fonte: INE

GRÁFICA 1. Variación no número de investigadores en EXC por CCAA entre 2006 e 2014. Sector Universidades

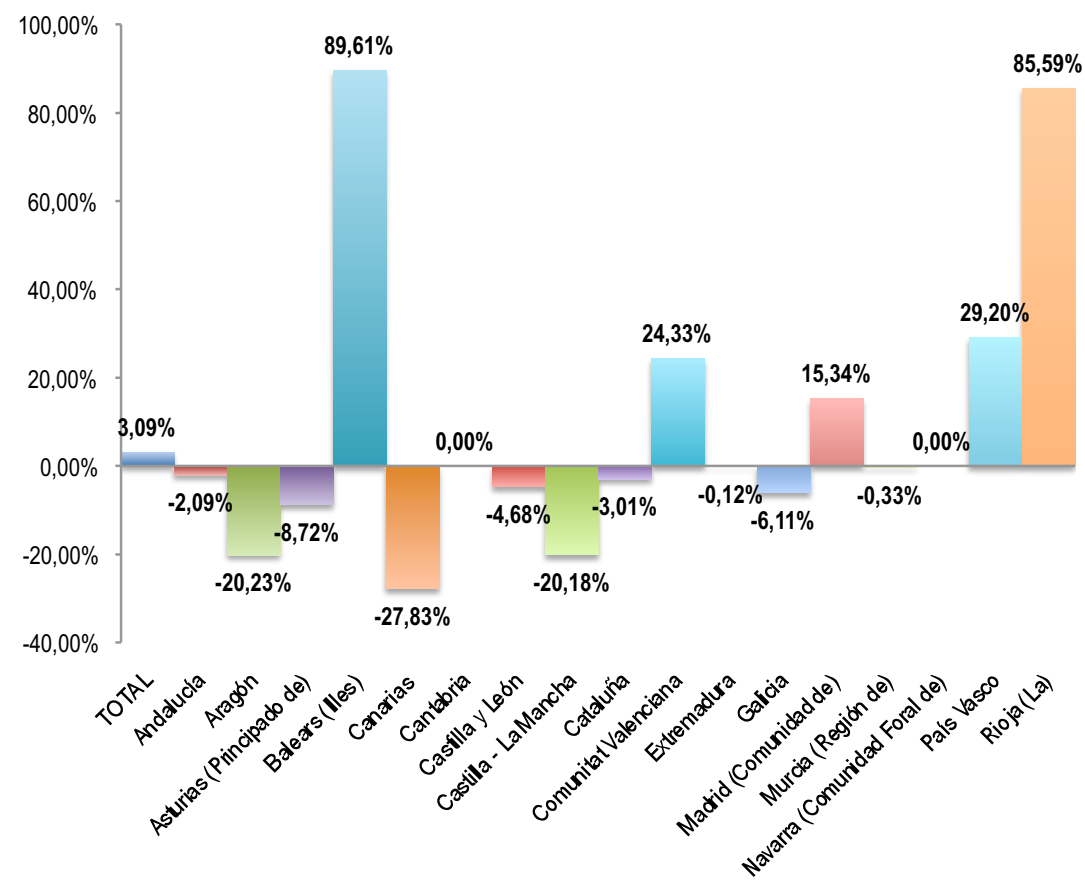

Fonte: Elaboración propia a partir das estatísticas de l+D do Instituto Nacional de Estatística

Neste contexto, Galicia ten unha evolución negativa dos seus activos investigadores, en maior medida que outras comunidades que neste período foron moi criticadas polas súas políticas de recortes, caso de Cataluña, e fronte a outras que, aínda no contexto da 
crise, acrecentan os seus efectivos, sendo os datos de Madrid e País Vasco especialmente significativos polo peso que teñen dentro do sistema de investigación do conxunto do Estado. Os datos mostran a desigual aplicación dos "recortes" aos recursos humanos de investigación nos últimos anos.

Os gastos internos do sector da empresa pasaron dun $44 \%$ ao $47 \%$ do gasto total realizado, pero aínda lonxe do $53 \%$ que supón no Estado español e e moito máis das cifras europeas. $E$ isto nun contexto no que o esforzo en I+D en Galicia descende notablemente. Se no ano 2006 os gastos en I+D respecto ao PIB supoñían o 0,89\% (o 1,2\% no conxunto do Estado), no 2010 supoñían 0,94\% fronte ao 1,4\% do Estado e no 2014 a porcentaxe descendía ao $0,87 \%$ fronte ao 1,23\% estatal. A lectura das cifras é clara: nun contexto de estancamento, cando non de caída do PIB, o esforzo en I+D diminúe ata niveis similares aos de 2005.

Non é este o camiño. Certamente, para ter un sistema de innovación que traballe na consecución dun desenvolvemento sostible social e economicamente, é precisa unha maior participación, tanto pola vía do financiamento como pola vía da execución, do sector privado, pero nun contexto de crecemento sostido en que o principal instrumento de que dispón o sistema para xerar avance no coñecemento no país, as universidades, non sexa prexudicado. $O$ sector público e o sector privado teñen funcións complementarias e imprescindibles ambas para poñer o coñecemento ao servizo do país. Por desgraza, algúns entenden que son funcións parcialmente substitutivas, e sobre a hipótese asumida como certa, sen contraste, de superior eficiencia dos axentes privados, impulsan a subordinación da función da universidade como mera subministradora de capacidades para a consecución de beneficios empresariais. $O$ que no contexto de fortes reducións nos recursos públicos á investigación, obriga ás universidades a xogaren neste campo de xogo.

Ao noso entender, unha das consecuencias negativas desta orientación estriba nun entendemento errado do papel que as universidades xogan na necesaria colaboración pública-privada. A dita colaboración debe desenvolverse dentro dunha estratexia propia e autónoma de cada universidade, conxurando os riscos de excesiva intromisión de intereses empresariais nas funcións que lles son propias ás institucións de educación superior. A investigación desenvolvida nas universidades non debe ser rexida por criterios propios das empresas privadas, pero tampouco debe ser o resultado da suma de intereses particulares, en moitos casos lexitimados polo aval científico que posúen, pero por veces desenfocados en canto a súa achega ao desenvolvemento do país. Certamente a lóxica da investigación é unha lóxica global, non local, e a relevancia científica responde a esa lóxica. A cuestión que ten que ocupar a nosa atención é o impacto local destes esforzos, asunto este que entendemos non está resolto, tampouco certamente fóra das universidades.

\section{Como conseguir facer o que queremos facer?}

A pregunta de como pode servir o sistema universitario e de investigación que temos para facer avanzar ao país social, económica e politicamente, obriga a pensar que queremos e que políticas poden deseñarse para conseguilo. E, polo tanto, que retorno podemos 
esixirlle tamén ao sistema de educación superior e innovación. O que esbozamos aquí son as posibilidades dalgunhas novas políticas galegas para o sistema de educación superior e para o sistema de investigación.

Son demasiadas posibilidades, moitas capacidades atoadas e mais unha crise de grande envergadura e dimensión, cando menos europea, o que temos neste intre. Xa que logo, este é o momento de elixir, seleccionar e priorizar políticas, máis que nunca antes. En troques diso, impera hoxe e nos últimos anos unha forma de "austeritarismo" que descoñece a ambición colectiva que permite o sistema de educación superior e de investigación deste país -ou de calquera outro país que dispoña dun sistema coma o noso-, dito o cal, resulta razoable pensarmos que as posibilidades e prioridades que aquí se formulan non sexan materializables sen unha mudanza política no país que permita unha mudanza das políticas. Porque o "auteritarismo" citado vén acompañado de inercia -que sempre é un poderoso factor para ter en conta- desde o inicio da crise.

A pregunta, daquela, resulta obvia: que facer con tanta capacidade de formación e coas nosas constatadas posibilidades da investigación? Como integrar e aproveitar esa realidade para o futuro das persoas, máis alá de resolvelo facendo emigrar aos mellores?

Aquí van algunha ideas de diferente magnitude e importancia, unhas máis doadamente practicables que outras, algunhas relativamente novas e outras sobexamente coñecidas pero non axeitadamente practicadas. Todas as propostas desta relación buscan contribuír a definir novas políticas para o sistema de educación superior e 0 de investigación de Galicia nunha dirección practicable e ambiciosa, ademais de rachar inercias e inanidades. E, por suposto, aspiramos a que sexan acrecentadas e melloradas.

1) Definir de vez as disciplinas e saberes que deben ser considerados estratéxicos na comunidade autónoma, en función das capacidades, intereses e posibilidades, de xeito que remate a vella e recorrente polémica das titulacións. De feito, 0 asunto está hoxe superado na súa expresión orixinal pola existencia dun catálogo non fixo de títulos, de modo que deben ser as universidades as que as organicen coa liberdade que os seus recursos e opcións estratéxicas lles permitan, en lugar de que as titulacións sigan sendo un asunto de limiares numéricos e sempre de negociación tendencialmente clientelar. De certo, non sería este o momento de introducir ámbitos novos aínda que de gran futuro, como a aeronáutica, pero si de aproveitar toda a expansión de hai 25 anos e, sobre todo, de atender ás lóxicas e posibilidades dispoñibles no mundo de hoxe e definibles por cada unha das tres universidades.

2) Nesta mesma liña cómpre alentar e acelerar a necesaria reforma interna das universidades galegas en termos organizativos. Favorecendo as mellores prácticas: fusión de facultades, departamentos e centros, para promover unidades máis rendibles, menos custosas e, sobre todo, máis axeitadas ás novas necesidades e competencias -definibles nos procesos de fusión- derivadas da adecuación á nova realidade dos graos-mestrado-doutoramento e da existencia con vida propia dunha nova estrutura que son os grupos de investigación. E neste camiño cumpriría favorecer orzamentariamente as boas prácticas das universidades e penalizar 
as malas a través de contratos programa que substitúan unha repartición permanentemente negociada desde criterios espurios.

3) Dotar de máis poder os órganos xerenciais internos das universidades para facer de contrapeso dos intereses corporativos nas decisións estratéxicas sería unha vía imprescindible para promover máis eficacia e rigor na xestión ordinaria e máis garantía na toma de decisións, no canto desa tutela intervencionista que dun tempo a esta parte está a imporse e que non propicia mellores resultados do sistema, senón pola contra decisións máis arbitrarias e peor informadas.

4) Os plans de financiamento, como fórmula asentada para programar as dotacións universitarias, poden seguir sendo un bo instrumento sempre que atendan e sirvan a liñas estratéxicas pensadas, informadas, definidas e baseadas en amplos acordos dos axentes implicados. En canto ás dotacións, requírese reverter a tendencia marcada pola obsesión na austeridade diferencial que marcan as cifras dos últimos anos, pero, por outra banda, pasou tamén o tempo de acrecentar dotacións ata limiares cada vez máis altos para facer render máis acaidamente os recursos dispoñibles.

5) Definir políticas de atracción de estudantes estranxeiros, para grao, mestrado e doutoramento que aproveiten as dotacións dos programa dispoñibles a nivel europeo. Unhas políticas que feitas desde Galicia deben ter tamén en conta algunhas vantaxes comparativas que poden ser aproveitadas polo noso sistema de educación superior, como a presenza organizada das comunidades galegas en moitos países de América ou, máis recentemente, a rede de máis de 30 centros de estudos galegos espallada por universidades de 17 países de Europa e América, ou 0 manexo dos dous idiomas ibéricos (alén do uso imprescindible do inglés).

6) Un acordo marco, un gran pacto entre comunidade autónoma, universidades, partidos e axentes sociais e económicos, sería factible e practicable no caso de xerárense e admitírense -de entrada no propio ámbito universitario- algunhas ideas fortes que poidan ser partilladas.

7) Promover a captación dos mellores recursos humanos para a docencia e a investigación, propios, retornados e alleos para a investigación resulta unha necesidade inescusable, como resultou sempre para un sistema que teña ambición de competir a nivel global para ser máis rendible tamén endoxenamente. Retomar programas de captación competitiva de investigadores (ao xeito dos sistemas lkerbasque ou Icrea) é unha necesidade ao alcance das posibilidades orzamentarias e das experiencias acumuladas neste país.

8) Investigar individualmente e favorecer desde as políticas públicas de investigación a selección da opción individual ou de grupo non é unha boa opción para manexar os recursos e tirarlles rendemento, co grao de madureza que ten xa o sistema científico galego.

9) Non podemos aspirar a ser Oxford, a ser un referente mundial nun feixe de áreas estratéxicas e colocarnos no cume das clasificacións. Oxford non se fixo en 50 
anos, mais si podemos aspirar a ser como a rexión de Dublín, como Noruega ou outros territorios europeos que teñen capacidades, dotacións, percorridos e contextos semellantes ao noso. Podemos aspirar a que a investigación repercuta no local e permita competir no global. Sermos excelentes na ciencia mundial non é incompatible con sermos excelentes na capacidade de transferir coñecemento aplicado para xerar riqueza para o país (social, económica, cultural...).

10) Sería necesario afondar naquilo que temos acumulado, cun aproveitamento local das liñas de investigación que nos dan vantaxe a nivel mundial (acuiculturaciencias do mar, ciencias da vida, nanotecnoloxía, sector agrogandeiro...) e dos recursos humanos formados en áreas consolidadas e emerxentes. En áreas que son xa ou deben ser estratéxicas porque encaixan coas nosas necesidades e lóxicas produtivas marcadas por unha longa traxectoria. Trátase de aproveitar aquilo en que somos mellores e que sabemos facer mellor e, asemade, definir outras áreas emerxentes ou novas na mesma liña, pero que non sempre tiveron o apoio ou o percorrido científico preciso (sector naval, enerxético, téxtil, vitícola). O naval é un exemplo de non aproveitamento local de vantaxes globais: tratándose dun sector claramente competitivo cómpre decidir unha política de I+D propia sabendo se é un sector de futuro ou para abandonar definitivamente;o que acontece neste ámbito é a proba de que algo facemos mal.

11) Urxe unha definición do sistema de innovación con propostas de novas políticas de innovación, empezando por revisar a relación universidade-empresa, anquilosada en marcos institucionais e prácticas non tan anovadas como requiren as mudanzas culturais e científicas das últimas tres décadas.

12) Sería necesario adelgazar as universidades da súa máis pesada carga investigadora naqueles centros e laboratorios (como os mixtos) con funcións máis aplicadas sen que perdan sinerxías nin capacidade de achega e incorporación para as universidades. Un programa de creación de centros tecnolóxicos que desenvolva capacidades que poden ficar estancadas por falla de desenvolvemento semella necesario.

13) En todo caso, a sinerxía e relación coa construción de plataformas e redes entre os centros de investigación da comunidade autónoma e os das universidades é unha necesidade no contexto dunha política científica de carácter estratéxico que debera ser definida para enmarcar desenvolvementos de futuro dos grupos de investigación.

14) Axudar a competir desde a Xunta de Galicia aos grupos, centros e institutos nos caladoiros europeos e extraeuropeos de fondos de investigación para facer máis rendibles as capacidades acumuladas, de xeito que algunhas unidades máis competitivas internacionalmente deben ter plans de sustentabilidade financeira/autofinanciamento a medio prazo, co fin de que nutran o sistema en vez de convertérense nunha carga cada vez máis pesada. 
15) Alianzas no mundo como política estratéxica deben ser formuladas para competir por proxectos; o País Vasco por intereses partillados e potencia industrial vén sendo xa un ámbito de referencia; Portugal ofrece desde hai tempo unha plataforma que alarga as nosas posibilidades; os países escandinavos polo seu dinamismo e por posuíren sectores tradicionais e emerxentes semellantes aos que 0 son aquí e un campo de intereses comúns. Estas e outras alianzas son necesarias estratexicamente para alén das vocacións dos investigadores e no marco da definición de políticas estratéxicas. Cómpre en todo caso formularse na definición desas alianzas se nos levan a ser cola de león ou cabeza de rato. E a que aspiramos na súa definición.

Un bo sistema é o que estimula a novidade, a innovación e as liñas de investigación máis rupturistas sobre bases definidas e sólidas, con xerarquías cientificamente fortes, pero normativamente débiles. Un bo sistema de educación superior é aquel que fai render as súas posibilidades para garantir maior benestar, maior equidade social e un futuro sustentable produtiva e ambientalmente. 
